\title{
Local fetal alcohol syndrome pioneer wins global award
}

The first person to identify and highlight the alarming prevalence of fetal alcohol spectrum disorder (FASD) in South Africa and respond with groundbreaking prevention, awareness, and training programmes, Professor Denis Viljoen, has received an international award.

Working in a population of around 30000 , served by some 300 shebeens, his platoon of dedicated social workers, nurses, therapists and volunteers reduced the FASD prevalence by $30 \%$ in just 3 years, the first ever decrease in FASD community prevalence in the world.

Viljoen, a geneticist, garnered the prestigious Henry Rosett Award for Outstanding Contributions to the Fetal Alcohol Spectrum Disorders field at the annual Research Society for Alcoholism Conference in San Fransisco on 23 June this year - the first time anyone outside North America has won it. The former paediatrician's remarkable interventions began after his observations during a government genetic rural outreach programme and while working at the Human Genetic Division at the University

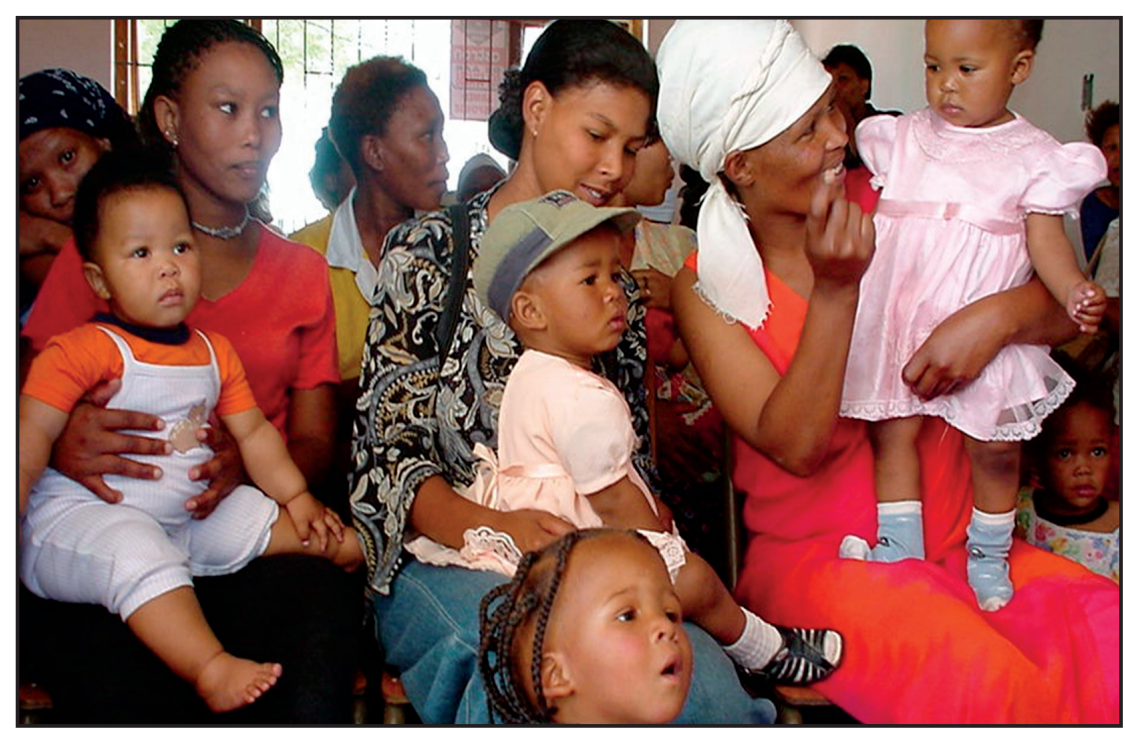

An everyday scene at the popular multi-purpose, FARR-initiated De Aar community centre, aka 'Die Pienk Huis'.

of Cape Town in the mid-1990s. He was shocked by the number of children referred to clinics with what he suspected was fetal alcohol syndrome (FAS), the most severe form of the fetal alcohol spectrum of disorders. FAS was little known in South Africa at the time. He shared his disquiet with delegates at an international meeting of the National Institutes of Health and the National Institute for Alcoholism and Alcohol Abuse - leading to his guiding a delegation from both organisations on a local field tour which resulted in their funding the first FASD prevalence study in 1997.

Viljoen told Izindaba in November 2010; 'at first there was anecdotal evidence that one in four women attending antenatal clinics in the province were drinking. Then I found out that one in ten kids being referred to the genetic clinic at Red Cross Children's Hospital had FASD. Also, when we audited kids attending schools for the mentally disabled, one in four had FASD. He chose Wellington in the Boland to initiate the research, uncovering a prevalence rate of $88 / 1000$ before moving to Upington (69/1 000) and De Aar (122/1 000 - the highest reported FASD rate anywhere in the world) - in 2002. In De Aar, reduced to a 'ghost town' after the South African Railways decentralised its national repair and manufacturing yard there in the mid-1990s, he encountered $80 \%$ joblessness and a slow 
Fransisco on 18 June, he said most of the FASD research from 1973 onwards (when FASS was first described by Kenneth L Jones) had initially been in North America (American Indian indigenous populations and inner city black populations) but slowly spread to South Africa, Europe and the UK. Biochemical and autopsy studies widened the field and neurologists and biochemists were among the specialists who received the award previously.

\section{According to a 2011 World Health Organization (WHO) report, South Africa has among the highest per capita alcohol consumption rates in the world and it continues to rise.}

'This recognises the work we've done. Our group only published in the international sphere and we've been recognised as a strong entity. This definitely enhances our chances of more funding. It also gives you power when you're speaking to politicians - they reckon you must be speaking the truth if you get such an award, so it's had some real knock-on effects,' he said with characteristic modesty. $\mathrm{He}$ said the acknowledgement was 'humbling' and he accepted it on behalf of the FASD fraternity in South Africa, FARR and other stakeholders - but more especially on behalf of the mothers 'who are prioritising the health of their unborn children by not using alcohol during pregnancy'.

According to a 2011 World Health Organization (WHO) report, South Africa has among the highest per capita alcohol consumption rates in the world and it continues to rise. South Africans are estimated to consume more than 5 billion litres of alcohol annually, which, excluding the consumption of sorghum beer, equates to 9 - 10 litres of pure alcohol per person. ${ }^{2}$ An estimated 130 people die daily as a result of alcohol-related causes in South Africa (46\% from injuries, 35\% from tuberculosis and HIV/AIDS, and 15\% from non-communicable diseases such as cancer, liver and cardiovascular diseases). In 2004, alcohol accounted for $6.3 \%$ of

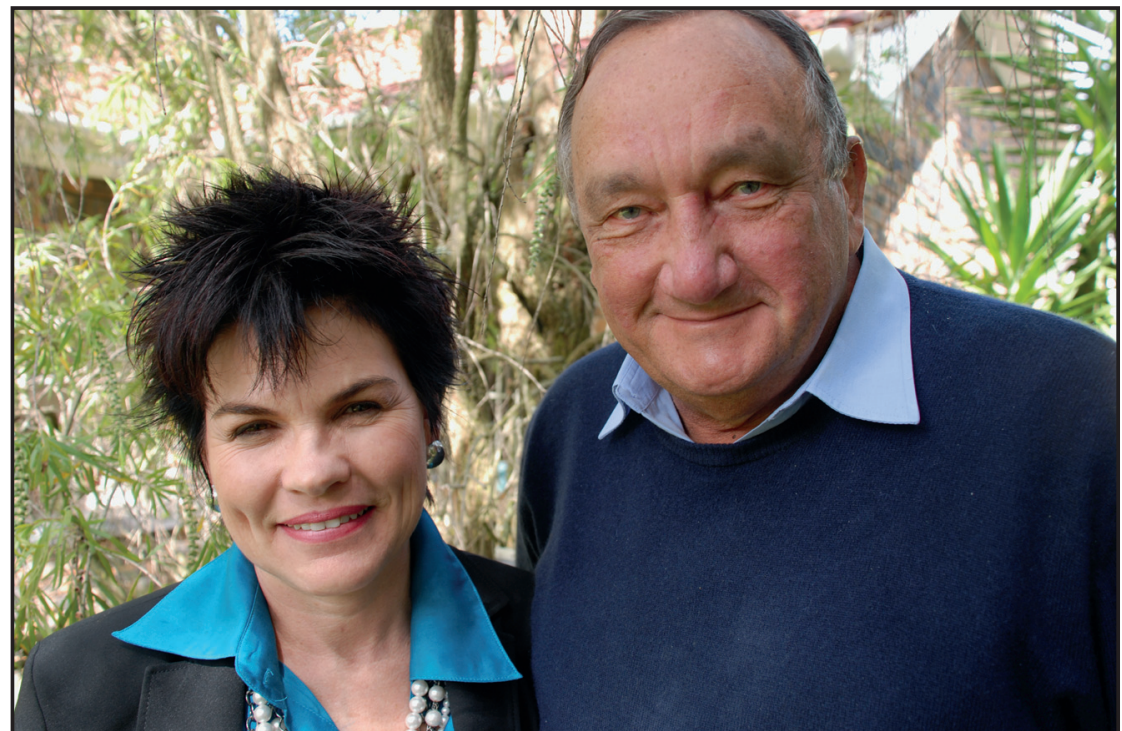

FARR founder, Professor Denis Viljoen and his CEO, Ms Leana Olivier.

DALYs lost in South Africa (i.e. years of life lost through dying prematurely) because of an alcohol-related event or living with a disability caused by alcohol. ${ }^{3}$ There are several communities in South Africa where the FASD-rate is higher than the HIV/AIDS rate - and further research will indicate just how widespread the threat really is.

\section{A 'safe' amount of alcohol probably does not exist for the pregnant woman.}

FAS is the third most common recognisable cause of mental retardation in the USA. Many of the features of FAS are secondary to the effect of alcohol on brain development. These include microcephaly, short palpebral fissures, the long smooth philtrum and thin vermilion of the upper lip, joint anomalies, altered palmar crease pattern, and mental retardation. Approximately $40 \%$ of babies born to alcoholic women and $11 \%$ of babies born to non-alcoholic moderately drinking women have evidence of the prenatal effect of alcohol. Alcohol, like other teratogens, causes a spectrum of defects. Thus, affected children may show great variability from the fullblown fetal alcohol syndrome to much milder effects of alcohol, some of which may not be obvious until school age. A 'safe' amount of alcohol probably does not exist for the pregnant woman. Depending on unknown factors, what may be a 'safe' amount for some women, may be devastating to the unborn baby of another. Two factors, the severity of the maternal alcoholism and the extent and severity of the pattern of malformation, seem to be most predictive of the ultimate prognosis for children with FAS. Any decision to file child abuse charges against a mother whose baby was prenatally exposed to alcohol should be based on the parent's ability to provide a stable home environment and not on whether the baby has features of FAS. FAS, the third most common recognisable cause of mental retardation, is completely preventable. 'All attempts must be made to educate people regarding the deleterious effect of alcohol, says Kenneth Jones in his seminal paper. ${ }^{4}$

\section{Chris Bateman \\ chrisb@hmpg.co.za}

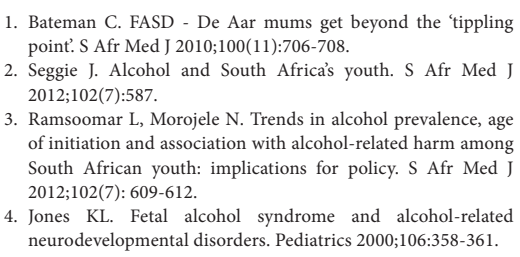
point'. S Afr Med J 2010;100(11):706-708

2. Seggie J. Alcohol and South Africa's youth. S Afr Med J 2012;102(7):587.

3. Ramsoomar L, Morojele N. Trends in alcohol prevalence, age of initiation and association with alcohol-related harm among South African youth: implications for policy. S Afr Med J 2012;102(7): 609-612.

4. Jones KL. Fetal alcohol syndrome and alcohol-related neurodevelopmental disorders. Pediatrics 2000;106:358-361.

S Afr Med J 2012;102(8):647-648.

DOI:10.7196/SAMJ.6083 